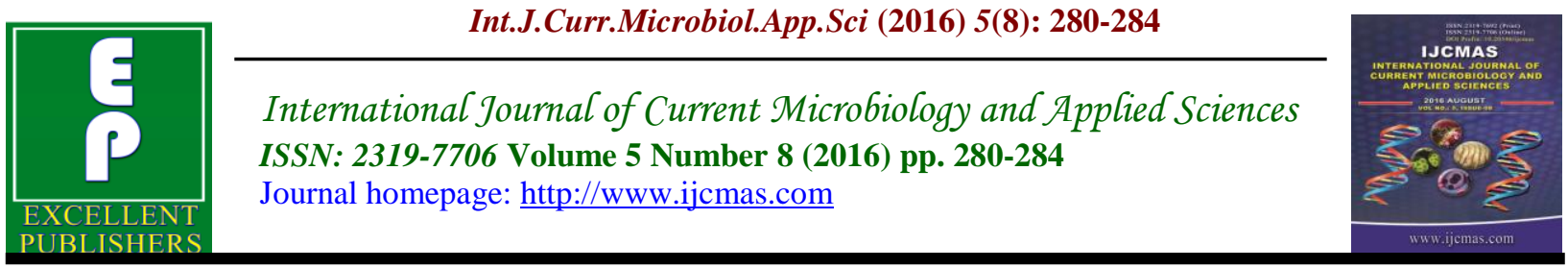

Original Research Article

http://dx.doi.org/10.20546/ijcmas.2016.508.029

\title{
Production of Ethanol by Saccharomyces cerevisiae Using Orange Peels and Banana Peels
}

\author{
V.A. Shinde ${ }^{1 *}$ and R.B. Patil ${ }^{2}$ \\ ${ }^{1}$ Department of Microbiology, Shankarrao Chavan Mahavidyalaya, Ardhapur, \\ Nanded, Maharashtra, India \\ ${ }^{2}$ Department of Botany, Shankarrao Chavan Mahavidyalaya, Ardhapur, Nanded, \\ Maharashtra, India \\ *Corresponding author
}

A B S T R A C T

Keywords

Saccharomyces cerevisiae,

Bio Processing, sachcharification.

Article Info

Accepted:

15 July 2016

Available Online:

10 August 2016
Nearly to 50,000 to 60000 crore of non processed products are thrown always in India, which are utilized to some extent to soil improvement but major portion is thrown away as waste. In present study efforts were made to produce valuable substance from some agro waste through the microbial fermentation process. Fossil fuels create a negative impact on our environment as greenhouse gas emissions are harmful. Production of ethanol (as an alternative fuel) from food and agricultural waste was done in present study by bio-processing. Wastes from fruits, such as banana, orange peels were subjected to simultaneous saccharification and fermentation for 7 days using Saccharomyces cerevisiae. The ethanol yield was determined at 24 hours interval. The optimal ethanol yields were $8.34 \% \mathrm{v} / \mathrm{v}, 7.45$ $\% \mathrm{v} / \mathrm{v}, 3.98 \% \mathrm{v} / \mathrm{v}$ and $2.58 \% \mathrm{v} / \mathrm{v}$ form banana, orange peels respectively. These indicate that banana peels ethanol yields was significantly higher than orange peels ethanol yield.

\section{Introduction}

World citrus production has increased significantly since 1980 's and the developed countries have expanded rapidly, in 2010 the orange production is estimated to reach 66.4 million MT, which represents a $14 \%$ increase compared to that of 1997-1999 (Girish Malhotra 2013).

Ethanol was first prepared synthetically in 1826, through the independent effort of Henry Hennel in Britain and S.G in France. Michael Faraday prepared ethanol by the acid-catalysed hydration of ethylene in 1828 , in a process similar to that used for industrial synthesis of ethanol today. Almost all ethanol is being produced by fermentations using Saccharomyces cerevisiae. Karsch et al. (1983) evaluated the potential of Zymomonas mobilis and Saccharomyces cerevisiae for ethanol production from glucose both aerobically and anaerobically. Saccharomyces cerevisiae commonly known as Baker's yeast has the ability to ferment a sugar 
solution poorly supplied with oxygen, resulting in the formation of alcohol and carbon dioxide. Zymomonas mobilis degrades sugars to pyruvate using the Entner-Doudoroff pathway. The pyruvate is then fermented to produce ethanol and carbon dioxide as the only products (Farombi and Britton, 1999).

Due to rapid exhaustion of fossil fuels there is an urgent need to resort to alternative fuels e.g. ethanol. The first large scale use of ethanol as a fuel happened during the early 1900s when petroleum supplies in Europe were short. Though ethanol is conventionally produced from petroleum byproducts, bio ethanol can alternatively be produced by fermentation technology using renewable raw material (Girish Malhotra, 2013).

In a study by Jayant Mishra et al. (2012), ethanol production from fruit peels of pineapple, orange and sweet lime was investigated. Total amount of sugar in pineapple, sweet lime and orange was $0.5,1$ and $0.8 \%$ respectively. In the solid state fermentation, pineapple agro residue gives a maximum yield around $2.16 \%$ with yeast.

Santra and Mandarin orange grows successfully in all trophical and subtrophical parts of the country. It tolerates more humidity in summer and winter than malta of sweet orange. The regiuon around Nagpur produces the finest oranges in the world. Orange is citrus waste. Orange peels after extracting juice is having composition of soluble sugars. These are sucrose, glucose, galactose, arabinose, xylose, rhamnose.

The use of mango peel as a source of pectin and fibre production also has been reported (Pandia et al., 2004). Grohmann et al., (1994; 1996) previously reported ethanol production from orange peel. Ethanol production from banana (Manikandan et al.,
2008) and pineapple peels (Ban-koffi and Han, 1990) were also investigated. Dried orange peels have a high content of pectin, cellulose and hemi cellulose, which make it suitable as fermentation substrate when hydrolyzed. Insoluble carbohydrates are present in the cell walls of the peels, particularly in the form of pectin, cellulose and hemicellulose.

Citrus (mainly orange) pulp and peels are cheap and suitable substance for growth and therefore efforts to utilize this waste for single cell protein (SCP) production have prevailed. Several microorganisms are proposed for SCP production from orange waste with or without chemical pretreatment such as aspergillus niger, trichoderma penicillium, Saccharomyces cerevisiae.

Saccharomyces cerevisiae is the most popular organism used for ethanol production due to its high ethanol yield and high tolerance. Nowadays, crops are the main source used for ethanol production. To achieve significant economic and environmental benefit large amount of food wastes can be utilized to produce ethanol. Utilization of fruit waste for bioethanol production is one of the best options. One example of raw material is pineapple waste that is converted to bioethanol (Hossain et al., 2008). The wastes contain valuable components such as sucrose, glucose, fructose and other nutrients (Sasaki et al., 1991). Lignocellulose is the major structural component of woody plants and non woody plants.

Therefore In present study efforts were made to produce valuable substance from some agro waste through the microbial fermentation process. The use of orange peels and banana peels as waste was done for ethanol production. 


\section{Materials and Methods}

\section{Routine Culture Maintenance}

Culture of Saccharomyces cerevisiae was maintained on YEPDA (1\% yeast extract, $2 \%$ peptone, $2 \%$ agar) slant stored at $4{ }^{\circ} \mathrm{C}$. The growth of Saccharomyces cerevisiae confirmed plate count methods (Yeast malt extract medium, at $28^{\circ} \mathrm{C}$.incubation period 23 days) (Kingsley Otulugbu, 2012).

\section{Preparation of Banana and Orange Peels for Ethanol Production}

Banana and Orange peels were washed and their outer coats are removed, cut in small pieces and kept it in the sunlight for few days and then kept in oven for drying and stored in refrigerator prior to use.

\section{Preparation of Growth Medium}

The growth medium (Inoculum Medium) prepared for ethanol production consists of glucose $(20 \mathrm{~g} / \mathrm{l})$, Ammonium sulphate $(0.8$ $\mathrm{g} / \mathrm{l}), \mathrm{KH}_{2} \mathrm{PO}_{4}(0.8 \mathrm{~g} / \mathrm{l})$, Magnesium sulphate $(4 \mathrm{~g} / \mathrm{l})$, Yeast extract $(3.2 \mathrm{~g} / \mathrm{l})$, in the production medium Glucose as carbon resource is replaced with agricultural waste (orange, banana peels) in $250 \mathrm{ml}$ of conical flask containing $100 \mathrm{ml}$ of distilled water(pH-5.5). The flasks were autoclaved at $121^{\circ} \mathrm{C}$ for 20 minutes. The cells of Saccharomyces cerevisiae were aseptically cultured in Inoculum Medium and incubated at $30^{\circ} \mathrm{C}$ for $24 \mathrm{hrs}$.

\section{Ethanol Production}

Medium (270 $\mathrm{ml})$ was prepared using agricultural waste (separately using Banana peels and Orange Peels) and transferred to a Conical Flask. The media was autoclaved at $121^{\circ} \mathrm{C}$ for 20 minutes and cooled. The medium was inoculated with $5 \% \mathrm{v} / \mathrm{v}$ of previous activate Saccharomyces cerevisiae.
The Flasks were cultured in aerobic and anaerobic conditions, for this purpose, the preparation was done in duplicates and one flaks was kept as it is and the other flask was sealed with paraffin wax to maintain anaerobic condition (for anaerobic process to follow seven flasks were prepared and numbered as day 1 to day 7). The samples were withdrawn at regular time intervals every $24 \mathrm{~h}$ till seven days of incubation and qualitative estimation of ethanol was done using potassium dichromate method and at seventh day of incubation the media was distilled and distillate collected was quantitatively estimated using specific gravity method.

\section{Primary Product Isolation}

The samples were centrifuged at $5000 \mathrm{rpm}$ for 5 minutes and stored at $-20^{\circ} \mathrm{C}$ for further analysis. The raw ethanol yield was measured by ethanol assay using potassium dichromate method. In this method 5 drops of distillate were treated with $2 \mathrm{ml}$ of $10 \%$ potassium dichromate and 5 drops of concentrated sulphuric acid. after this the tube was gently heated to observe colour change to green. The quantitative estimation of alcohol produced was done by using specific gravity method using AOAC table.

Quantitative estimation of Ethanol by specific gravity method using AOAC table:

In this method the dry and empty specific gravity bottles were taken and weighed, then the weight of distilled water was taken. Then specific gravity bottles were again dried and now filled with the distillate (alcohol produced in the fermentation) and weight of distillate was taken. Using these observations specific gravity was calculated and using AOAC table percentage of alcohol in the distillate was estimated. 


\section{Results and Discussion}

Orange peels is an efficient material for production of ethanol rather than burning it with other agricultural wastes. Ethanol production from orange peels can satisfy the growing need of ethanol, present study can be economical and also reduce the agricultural waste. The production media consisting of oven dried substrate (Orange peels and banana pees respectively) (20gms) was used and volume was made up to 250 $\mathrm{ml}$ and $\mathrm{pH}$ was adjusted to 5.5.

Table.1 Quantitative Estimation of Ethanol by Specific gravity method:

\begin{tabular}{|l|l|l|l|l|}
\hline $\begin{array}{l}\text { Sr } \\
\text { NO }\end{array}$ & $\begin{array}{l}\text { Weight of } \\
\text { distilled water }\end{array}$ & $\begin{array}{l}\text { Weight of } \\
\text { distillate }\end{array}$ & Specific Gravity & $\begin{array}{l}\text { \% of alcohol Estimated using } \\
\text { AOAC table }\end{array}$ \\
\hline 1 & 49.97 & 48.79 & 0.976 & $18.62 \%$ \\
\hline 2 & 49.52 & 47.14 & 0.951 & $37.71 \%$ \\
\hline 3 & 49.97 & 48.71 & 0.970 & $23.72 \%$ \\
\hline 4 & 49.52 & 47.74 & 0.964 & $28.63 \%$ \\
\hline
\end{tabular}

Table.2 Yield of ethanol by Different Substartes in aerobic and anaerobic conditions

\begin{tabular}{|l|l|l|l|l|}
\hline Substrate & \multicolumn{3}{|c|}{ Orange Peels } & Banana Peels \\
\hline Condition & Aerobic & Anaerobic & Aerobic & Anaerobic \\
\hline$\%$ of Alcohol & $18.62 \%$ & $37.71 \%$ & $23.72 \%$ & $28.63 \%$ \\
\hline
\end{tabular}

For inoculums preparation production medium was used and was inoculated with culture of Saccharomyces cerevisiae to prepare inoculum. Fresh fermentation media (prepared by using orange peels and banana peels) was inoculated with an activated culture of Saccharomyces cerevisiae (Inoculum). The culture was transferred to Conical Flasks. The Flasks were kept in an incubator at $28^{\circ} \mathrm{C}$. The samples were withdrawn in every $24 \mathrm{hrs}$ and the changes in ethanol concentration were qualitatively estimated and at the end of fermentation at seventh day changes in ethanol concentration were quantitatively estimated using specific gravity method (Table 1 and 2 and it was seen that the agricultural wastes used that is, Sacchromyces cerevisiae used banana peels and orange peels efficiently for ethanol production in anaerobic condition than in aerobic condition and as substrate orange peels showed highest ethanol production $(37.71 \%)$ than banana peels
$(28.63 \%)$. From the experiments, it is proved that the ethanol yield could be produced from Orange peels and Banana Peels as agricultural waste as the substrates. Maximum activity is obtained by using Orange peels as a substrate at $28^{\circ} \mathrm{C}$.

\section{References}

Ban-koffi, L., Han, Y.W. 1990. Alcohol production from pineapple waste. World J. Microbiol. Biotechnol., 6: 281-284.

Farombi, E.O. and Britton, G. 1999. 'Antioxidant activity of palm oil carotenes in organic solution: effects of structure and chemical reactivity'. Food Chem., 64: 315-21.

Girisha Malhotra, Shilpa, C. and Chanchal. 2013. Alcohol Production from Fruit and Vegetable Waste International $J$. Appl. Engi. Res., Vol 8 (15) pp. 17491756. 
Grohmann, K., Baldwin, E.A., Buslig, S.B. 1994. Production of ethanol from enzymatically hydrolyzed orange peel by yeast Saccharomyces cerevisiae. Appl. Biochem. Biotechnol., 45/46: 383-388.

Grohmann, K., Cameron, G.R., Buslig, S.B. 1996. Fermentation of orange peel hydrolysates by ethanogenic E. coli: effects of nutrient supplements. Appl. Biochem. Biotechnol., 57/58: 383-388.

Hossain, A.B.M.S., Abu Saleh, A., Salleh, A.N., Boyce, P., Prothim Naquidin. M. 2008. Bioethanol production from agricultural waste biomass as a renewable bioenergy resource in biomaterials. The 4th Inter. Biomed. Engineering conference Nikko Hotel, Kuala Lumpur, Malaysia. 26 Jun 2008 to 28 Jun.

Jayant Mishra. et al., 2012. A comparative study of ethanol production from various agro residues by using Saccharomyces cerevisiae and Candida albicans, J. Yeast and Fungal Res., 3(2): 12 - 17.
Karsch, T., Stahl, U., Esser, K. 1983. Ethanol production by Zymomonas and Saccharomyces, advantages and disadvantages. Eur. J. Appl. Microbiol. Biotechnol. 18: 387-391.

Kingsley Otulugbu. 2012. Production of Ethanol from Cellulose (Sawdust). Degree Thesis on Plastic Technology.

Manikandan, K., V. Saravanan and T. Viruthagiri. 2008. Kinetics studies on ethanol production from banana peel waste using mutant strain of Saccharomyces cerevisiae. Indian J. Biotechnol., Vol 7, pp 83-88.

Pandia, B., Stephen, K., Louise, W. 2004. Texture and distribution of pectic substances of mango as affected by infusion of pectin methyl esterase and calcium. J. Sci. Food Agric., 8: 14931499.

Sasaki, K., Watanabe, M., Tanaka, T. and T. Tanaka. 2002. Biosynthesis, biotechnological production and applica of 5-aminolevulinic acid. Appl. Microbiol. Biotechnol., 58: 23-29.

\section{How to cite this article:}

Shinde, V.A., and Patil, R.B. 2016. Production of Ethanol by Saccharomyces cerevisiae Using Orange Peels and Banana Peels. Int.J.Curr.Microbiol.App.Sci. 5(8): 280-284. doi: http://dx.doi.org/10.20546/ijcmas.2016.508.029 